\title{
El interés superior de la infancia considerada indígena
}

\section{The higher interest of children considered indigenous}

https://doi.org/10.15332/iust.v0i15.2089

\author{
Mayte Hernández García \\ Profesora de tiempo completo en la Facultad de Derecho y Ciencias Sociales de la Universidad Autónoma "Benito \\ Juárez" de Oaxaca (UABJO); líder del Cuerpo Académico "Derecho, Salud, Medio Ambiente y Género en Servicio de \\ la Sociedad" de la UABJO; maestra en Derecho Privado; doctoranda en Derecho de la Facultad de Derecho y Ciencias \\ Sociales de la UABJO. \\ Correo electrónico: maytehg21d@gmail.com
}

\section{María del Rosario Molina González}

Doctora en Derecho por la Universidad de Sonora, maestra en Amparo por la Universidad Autónoma de Durango, docente e Investigadora del Departamento de Ciencias Sociales, Universidad de Sonora, Unidad Regional Sur, México. Líder de Cuerpo Académico Dogmática Jurídica y Proceso Educativo. Tendencias Actuales (UNISON-CA-165), Líneas de investigación: garantismo, ciencias penales y victimológicas; género, derechos humanos y justicia.

Correo electrónico: rmolina@navojoa.uson.mx

\section{Lidia del Rocío Reyes Ramírez}

Maestra y doctora en Derecho por la Universidad Autónoma "Benito Juárez" de Oaxaca; integrante del Cuerpo Académico "Derecho, Salud, Medio Ambiente y Género en Servicio de la Sociedad.

Correo electrónico: camiler3@yahoo.com.mx

\section{William Méndez García}

Maestro en Procuración de justicia y Juicio Oral por la Universidad del Valle de México, Campus Puebla, doctorando en la Facultad de Derecho y Ciencias Sociales de la UABJO; docente de la Facultad de Derecho y Ciencias Sociales de la UABJO, colaborador del Cuerpo Académico Derecho, Salud, Medio Ambiente y Género en Servicio de la Sociedad. Correo electrónico: William_mendez_garcia@yahoo.com.mx

\section{Omar Huertas Díaz}

Abogado, profesor asociado, doctor (C) en Derecho por la Universidad Nacional de Colombia, Ph.D. en Ciencias de la Educación por la Universidad Simón Bolivar; Mg. en Derecho Penal por la Universidad Libre; máster en Derechos Humanos, Estado de Derecho y Democracia en Iberoamérica por la Universidad de Alcalá, España; Mg. en Educación por la Universidad Pedagógica Nacional; Socio de la Fundación Internacional de Ciencias Penales FICP; miembro de honor de la Fundación de Victimología; miembro Honorario Asociación Colombiana de Criminología.

Correo electrónico: ohuertasd@unal.edu.co

\section{Resumen}

En los sistemas constitucionales modernos se han previsto y signado diversos instrumentos internacionales y creado todo un bloque jurídico en donde se prevén derechos específicos para las niñas, niños y adolescentes; en los que se establece la responsabilidad que todas las autoridades e instituciones públicas o privadas tienen sobre su bienestar, categorizada como un sector social vulnerable, el problema se agrava con una nueva categoría sospechosa de pertenencia a un grupo étnico donde se acentúan las condiciones de marginación, espacios que por mucho tiempo se ha excluido del debate jurídico, de las políticas públicas y que requiere un redimensionamiento efectivo. El presente artículo, tiene como objetivo hacer algunas aclaraciones conceptuales y jurídicas, abordaje que se realiza como estudio dogmático y normativo, referenciado desde el entorno jurídico social indígena en Oaxaca, México.

Palabras clave: Interés superior de la infancia, niño, vulnerabilidad, indígena. 


\section{Abstract}

In modern constitutional systems, various international instruments have been planned and signed and a whole legal bloc has been established, which provides for specific rights for girls, boys and adolescents; which establishes the responsibility that all public and private authorities and institutions have for their well-being, categorized as a vulnerable social sector, the problem is aggravated by a new suspicious category of belonging to an ethnic group where the conditions of marginalization are accentuated, spaces that for a long time have been excluded from the legal debate, from public policies and that require an effective resizing. The present article, in its essay modality, aims to make some conceptual and legal clarifications, approach that is carried out as a dogmatic and normative study, referenced from the indigenous social legal environment in Oaxaca, Mexico.

Keywords: Higher interest in childhood, boy, vulnerability, indigenous.

\section{Résumé}

Dans les systèmes constitutionnels modernes, divers instruments internationaux ont été planifiés et signés et un bloc juridique entier a été établi, qui prévoit des droits spécifiques pour les filles, les garçons et les adolescents; qui établit la responsabilité que toutes les autorités et institutions publiques et privées ont pour leur bien-être, catégorisé comme un secteur social vulnérable, le problème est aggravé par une nouvelle catégorie suspecte d'appartenance à un groupe ethnique où les conditions de marginalisation sont accentuées, des espaces qui ont longtemps été exclus du débat juridique, des politiques publiques et qui nécessitent un redimensionnement efficace. Le présent article, dans sa modalité d'essai, vise à faire quelques clarifications conceptuelles et juridiques, approche qui est réalisée comme une étude dogmatique et normative, référencée à partir de l'environnement juridique social autochtone à Oaxaca, au Mexique.

Mots-clés: Intérêt supérieur dans l'enfance ; enfant, vulnérabilité, autochtone. 


\title{
El interés superior de la infancia considerada indígena
}

\author{
María del Rosario Molina González \\ Omar Huertas Díaz \\ Mayte Hernández García \\ Lidia del Rocio Reyes Ramírez \\ William Méndez García
}

\section{INTRODUCCIÓN}

En el presente análisis se parte de la necesidad de delimitar conceptual y jurídicamente sobre las categorías de infancia, niño, niña o adolescente indígena, sobre el principio de interés superior del menor (así llamado en los tratados internacionales y en diversas legislaciones existentes), vulnerabilidad social y vulnerabilidad jurídica de ese grupo social y sobre los mecanismos de tutela jurisdiccional. Delimitando igualmente a la entidad de la República mexicana que posee el mayor número de municipios y comunidades que hablan alguna lengua indígena, referencia que México es una nación pluricultural, según el Instituto Nacional de Estadística durante 2015, 6.5\% de la población del país habla alguna lengua indígena, de los cuales 494 municipios más del $40 \%$ de sus habitantes son hablantes de lengua indígena y en Oaxaca hay 245 municipios en esta situación (Instituto Nacional de Estadística y Geografía, 2016).

La consideración de los derechos humanos bajo los principios rectores de universalidad, interdependencia, indivisibilidad y progresividad, junto a las condiciones de igualdad de las personas en México, exige el abordaje del tema a partir de la identificación de tres categorías sospechosas de análisis, como lo son:

Niño, niña, adolescente; indígena, pobre. Entendiendo por categoría sospechosa, aquellas que la Constitución Política de los Estados Unidos Mexicanos contempla en alguno de los criterios enunciados en el último párrafo del artículo 1o. constitucional, tales como: 
El origen étnico o nacional, el género, la edad, las discapacidades, la condición social, las condiciones de salud, la religión, las opiniones, las preferencias sexuales, el estado civil o cualquier otra que atente contra la dignidad humana y tenga por objeto anular o menoscabar los derechos y libertades de las personas (Constitución Política de los Estados Unidos Mexicanos) ${ }^{1}$.

Y sobre las cuales el operador jurídico, de cualquier ámbito del quehacer público debe realizar con especial atención y cuidando que prevalezca, en todo caso, la dignidad y el interés superior de la niñez.

Actualmente los derechos humanos de los infantes oaxaqueños considerados indígenas, son vulnerados. Es un hecho notorio que en algunas calles o cruceros de la ciudad de Oaxaca y en las comunidades indígenas, hay niñas y niños que viven en condiciones alejadas de lo que implica la dignidad humana, no solo por aquellos que viven en condición de calle, sino adicionalmente en extrema pobreza, desnutridos y consecuentemente bajas condiciones de salud, bajo nivel educativo, trabajando o durmiendo a la intemperie. Ejemplificativamente en este artículo, referimos algunos datos estadísticos sobre las condiciones en que viven esos menores de edad en Oaxaca, cómo la situación actual colisiona con las directivas de los derechos humanos y con el principio rector del interés superior de la niñez; transformando a un derecho de papel ante la ineficacia de los programas y políticas públicas que redunden en mejores niveles de salud, educación, de subsistencia y desarrollo de la infancia indígena, focalizada desde la condición de la población de Oaxaca, entidad de mayor representación indígena en México.

\section{CONSTRUCCIÓN DOGMÁTICA AL TEOTMAIL.MA}

\section{a. Concepto legal de niño}

La Convención Sobre los Derechos del Niño, en su primer artículo define, "Niño", textualmente establece en su numeral 1: "Para los efectos de la presente Convención, se entiende por niño todo ser humano menor de dieciocho años de edad, salvo que, en virtud de la ley que le sea aplicable, haya alcanzado antes la mayoría de edad", y en

1 Suprema Corte de Justicia de la Nación, Época: Décima Época, Registro: 2003284, Instancia: Primera Sala, Tipo de Tesis: Aislada, Fuente: Semanario Judicial de la Federación y su Gaceta, Libro XIX, abril de 2013, Tomo 1, Materia(s): Constitucional, Tesis: 1a. XCIX/2013 (10a.). Este criterio ha integrado la jurisprudencia 1a./J. 66/2015 (10a.), publicada el viernes 30 de octubre de 2015, a las 11:30 horas en el Semanario Judicial de la Federación y en la Gaceta del Semanario Judicial de la Federación, Décima Época, Libro 23, Tomo II, octubre de 2015, página 1462, de título y subtítulo: "IGUALDAD. CUANDO UNA LEY CONTENGA UNA DISTINCIÓN BASADA EN UNA CATEGORÍA SOSPECHOSA, EL JUZGADOR DEBE REALIZAR UN ESCRUTINIO ESTRICTO A LA LUZ DE AQUEL PRINCIPIO”. 
ese sentido, constriñe a ciertas obligaciones de los Estados de adoptar medidas para la protección de los niños (Molina, Huerta, Suárez, 2017).

En este artículo se emplea la palabra niño en sentido general por lo que a lo largo de este trabajo cuando se utilice ese término, se estará refiriendo también a las niñas y adolescentes, considerando en la expresión más generalizada de la niñez, como grupo socialmente protegido por el sistema jurídico.

\section{b. Aclaraciones sobre el contenido y alcance del principio "Interés Superior del Niño"}

La Corte Interamericana ha manifestado que el principio "interés superior del niño" implica que el desarrollo de este y el ejercicio pleno de sus derechos deben ser considerados como criterios rectores para la elaboración de normas y aplicación de estas a todos los ordenamientos relativos a la vida del niño. Y reconoce que:

Este principio regulador de las normas de los derechos del niño se funda en la dignidad misma del ser humano, en las características propias de los niños, y en la necesidad de propiciar el desarrollo de éstos, con pleno aprovechamiento de sus potencialidades así como en la naturaleza y alcances de la Convención sobre los Derechos del Niño" (O’Donnell, s.f., p. 814).

La Declaración de los Derechos del Niño (1959) y a la Convención sobre los Derechos del Niño son las legislaciones internacionales en las que se integra la categoría o principio de "Interés superior del niño", mismo que en la literatura, indistintamente puede ser referenciado como interés superior de la niñez o de la infancia.

En suma, la Declaración de los Derechos del Niño, en su principio II prevé que; al promulgarse leyes se debe atender al interés superior del niño, y la Convención sobre los Derechos del Niño, en el artículo 3 establece que todas las autoridades e instituciones públicas y privadas, en los asuntos concernientes a este grupo etario deben considerar el interés superior del niño.

Respecto de la categoría interés superior del niño, algunos autores han discutido sobre su indeterminación porque esa categoría no se define exactamente en los textos normativos internacionales. Tomando en cuenta lo preceptuado por el artículo 4 de la Constitución mexicana y la Ley para la protección de los derechos de niños, niñas y adolescentes; “el interés superior del menor" es y será un concepto jurídico indeterminado, y consecuentemente su contenido se relaciona con las circunstancias concretas de las personas que intervienen en la relación jurídica, es decir, el interés del menor ha de entenderse siempre tomando en cuenta todos los datos que conforman la situación del menor (González y Rodríguez, s.f., p. 22).

En Nicaragua se proporciona un concepto legal de: interés superior de la niña, niño y adolescente. El Código de la Niñez y la Adolescencia, Ley número 287, de 1998, adoptado en Nicaragua, establece: "Se entiende por interés superior de la niña, niño y adolescente, todo lo que favorezca su pleno desarrollo físico, psicológico, 
moral, cultural, social, en consonancia con la evolución de sus facultades que le beneficie en su máximo grado" (Ley No. 287, del 24 marzo 1998).

Dicho de otra forma: El interés superior del niño consiste en la más amplia satisfacción de todos los derechos establecidos en la Convención sobre los Derechos del Niño (Garrido, 2013).

Miguel Cillero Bruñol opina que el interés superior del niño es un principio jurídico garantista (s.f.). Dados los derechos reconocidos en las legislaciones que prevén derechos específicos de la niñez; por lo tanto ese principio es la plena satisfacción de los derechos de los niños, continua en su expositiva el autor, que el interés superior del niño es la satisfacción integral de sus derechos.

Del análisis, se coincide con Cillero, al relacionar que en el artículo tercero de la Convención sobre los Derechos del Niño se delinean las siguientes características: es una garantía, ya que toda decisión que concierna al niño debe considerar primordialmente sus derechos; es de una gran amplitud, ya que no solo obliga al legislador sino también a todas las autoridades e instituciones públicas, privadas y a los padres; también es una norma de interpretación o de resolución de conflictos jurídicos. Finalmente, es una orientación o directriz política para la formulación de políticas públicas para la infancia, permitiendo orientar las actuaciones públicas hacia el desarrollo armónico de los derechos de todas las personas, niños y adultos, contribuyendo, sin dudas, al perfeccionamiento de la vida democrática (Cillero, s.f.).

Tal indefinición del interés superior del menor en el contexto legislativo para la experiencia mexicana puede vincularse a diverso precedente, pronunciado en décima época, de enero de 2017, donde la Sala Segunda de la Suprema Corte de Justicia de la Nación (2017), en el núcleo argumentativo sostuvo que:

...debe destacarse que el interés superior del menor es un concepto triple, al ser: (I) un derecho sustantivo; (II) un principio jurídico interpretativo fundamental; y (III) una norma de procedimiento. El derecho del interés superior del menor prescribe que se observe "en todas las decisiones y medidas relacionadas con el niño", lo que significa que, en "cualquier medida que tenga que ver con uno o varios niños, su interés superior deberá ser una consideración primordial a que se atenderá", lo cual incluye no sólo las decisiones, sino también todos los actos, conductas, propuestas, servicios, procedimientos y demás iniciativas...

De suerte tal que, en la directiva del interés superior del menor, como derecho sustantivo, principio y norma de procedimiento, queda implicada toda autoridad, indistintamente sea del sector público como privado, consecuentemente las acciones atenderán a esa consideración de tutela y de asegurar las mejores condiciones de desarrollo del niño, niña, adolescente, vinculado además al principio de progresividad y no regresión de los derechos humanos. 


\section{c. Vulnerabilidad social de la niñez considerada indígena}

Por el solo hecho de ser niño, se es vulnerable a sufrir fácilmente violaciones en sus derechos fundamentales, situación que se adicional si se le adiciona la característica de ser considerado indígena; porque dentro de las características propias de los grupos étnicos, es relacional la precariedad económica, lo cual impide a la persona a gozar de los satisfactores primordiales, en consecuencia, de las mejores condiciones de dignidad y de disfrute de los derechos fundamentales.

En cuanto a la vulnerabilidad de la niñez considerada indígena, tomamos en cuenta lo sostenido en 2008, por el sociólogo Rodolfo Stavenhagen en uno de sus artículos donde estableció que:

Los pocos datos que hay sobre niños indígenas son alarmantes. Según cifras oficiales, $56 \%$ de los niños indígenas del país padece desnutrición y al menos 690,000 menores de 4 años padecen graves problemas de desnutrición y estatura. La mortalidad infantil es mucho más frecuente en niños indígenas que en la población infantil promedio del país (Stavenhagen, s.f.).

Según estudios realizados entre el Centro de Investigación y Estudios Superiores en Antropología Social (CIESAS) Unidad Pacífico Sur y UNICEF México, en el estado de Oaxaca hasta el 2010 se obtuvieron como datos -cualitativos y cuantitativos- de la situación de la población en comento, a saber:

a) Oaxaca es el estado con la mayor presencia numérica de población indígena y con la mayor diversidad etnolingüística de México (UNICEF, s.f.).

b) En Oaxaca vive un gran número de pueblos y comunidades indígenas que, debido a su acceso desigual a bienes y servicios, ven obstaculizado el cumplimiento de sus derechos y se caracterizan por presentar mayores niveles de rezago y marginación en comparación con la población no indígena (UNICEF, s.f.).

c) Oaxaca es considerada una entidad de muy alta marginación, ocupando el tercer lugar a nivel nacional en 2010 con un índice de marginación de 80.48, solo precedida por Guerrero y Chiapas con 88.72 y 84.14, respectivamente. Entre 2000 y 2010, con base en información del CONAPO, en Oaxaca hay 570 municipios, y según las estadísticas 6 de cada 10 municipios oaxaqueños presentan condiciones de marginación elevados (UNICEF, s.f.).

d) En materia de acceso a servicios públicos y condiciones de las viviendas, en $2010,22.8 \%$ de los oaxaqueños no tenía agua entubada en su casa y $29.2 \%$ carecía de drenaje, en comparación con $8.5 \%$ y $9.7 \%$, respectivamente, a nivel nacional... En cuanto al suministro de energía eléctrica, 5.7\% de las viviendas no están enlazadas a la red y casi una de cada cinco casas $(18.7 \%)$ tiene piso de tierra, en comparación con porcentajes mucho más bajos a nivel nacional ( $2.2 \%$ y $6.2 \%$, respectivamente) (UNICEF, s.f.).

e) Adicionalmente, en 2006 se promulgó en Oaxaca la Ley de Justicia para 
Adolescentes (LJA) y en 2008 se efectuaron reformas al Código Penal para protegerlos contra actos que afecten su dignidad y desarrollo. La LJA reconoce el derecho de los adolescentes en conflicto con la ley penal al debido proceso, así como otras consideraciones que observen el principio de proporcionalidad y promuevan la resocialización (UNICEF, s.f.).

f) $\mathrm{Y}$ con respecto a los infantes que trabajan, tenemos las siguientes cifras: 159,287 personas entre 5 y 17 años trabajando en el estado, lo que representó $15 \%$ de la población total en ese rango de edad. De ellos, $36.8 \%$ eran niñas y $63.7 \%$ niños. Dos de cada diez niños (19\%) y una de cada diez niñas $(11 \%)$ se encontraban trabajando en Oaxaca en 2011 (UNICEF, s.f.).

Además, a los datos que de por sí contextualizan la situación, en la actualidad, debe agregarse que es un hecho notorio que en las calles y cruceros de la ciudad de Oaxaca hay niñas y niños indígenas trabajando, vendiendo algo, limpiando coches o inducidos a la mendicidad. Es fácil advertir su situación de calle al pernoctar en la vía pública y que su aspecto físico refleja desnutrición y falta de higiene. Por lo tanto, en Oaxaca no se cumple en los extremos con el principio "Interés superior del niño", porque el grupo referido no goza de cuidados especiales, ni se les tutela eficientemente el goce y disfrute de los derechos humanos, previstos en sendos documentos, que integran el bloque de constitucionalidad nacional, como internacional, obligaciones que devienen de las reformas de 10 de junio de 2011. Entre ellas:

Se obliga al Estado mexicano a reconocer los derechos humanos y la dignidad humana, asimismo se incluyen varios principios en la materia y la obligación, por parte de este país, de respetar, observar y cumplir con los tratados internacionales que México ha aceptado y ratificado (Manrique, Gómez, Martínez, 2015).

Los cuales están correlacionados al presente análisis.

\section{d. Referente legal básico}

La Declaración de Ginebra sobre los Derechos del Niño de 1924 es la primera declaración que se manifiesta específicamente sobre los derechos de los niños y reconoce la existencia de derechos específicos para las niñas y los niños, además de la responsabilidad de las personas adultas sobre su bienestar (Jiménez, 2001).

Paulí Dávila resume los derechos protectores de esta declaración, en los siguientes ejes: alimento, cuidado, ayuda, acogida y socorro, educación, reinserción del niño delincuente y protección en caso de peligro (Dávila y Naya, 2006). Elementos que son indispensables para un sujeto que se encuentra en desarrollo, en los cuales deben intervenir no solo las autoridades, sino la sociedad en conjunto, pues de acuerdo con lo señalado por Huertas Díaz "la problemática de la delincuencia juvenil es un tema de total relevancia para todos los sectores de la sociedad, ya que pareciera que es un fenómeno que no tiene control y sigue en crecimiento constante” (Huertas, 2016). 
La ONU en 1948 aprobó la Declaración Universal de los Derechos Humanos; en la que incluye implícitamente cuestiones sobre derechos de la infancia, aunque no los menciona específicamente.

En 1959 se aprobó la Declaración de los Derechos del Niño, ante las necesidades y protección especiales de los niños (contiene 10 principios) (Pedroza de la Llave, García, 2003). El principio II establece que:

El niño gozará de una protección especial y dispondrá de oportunidades y servicios, dispensado todo ello por la ley y por otros medios, para que pueda desarrollarse física, mental, moral, espiritual y socialmente en forma saludable y normal, así como en condiciones de libertad y dignidad. Al promulgar leyes con este fin, la consideración fundamental a que se atenderá será el interés superior del niño.

El primer tratado vinculante sobre la infancia es la Convención sobre los Derechos del Niño (firmada el 20 de noviembre de 1989), es un tratado que prevé normas para la protección de la infancia y los derechos del niño, pondera la protección especial que deben tener todas las niñas y niños; por no haber alcanzado el pleno desarrollo físico y mental. En su artículo primero proporciona el concepto de niño (ONU, 1989). El artículo 2 en su segunda parte prevé:

Los Estados partes tomarán todas las medidas apropiadas para garantizar que el niño se vea protegido contra toda forma de discriminación o castigo por causa de la condición, las actividades, las opiniones expresadas o las creencias de sus padres, o sus tutores o de sus familiares (ONU, 1989).

En el numeral 3.1 literalmente estipula:

En todas las medidas concernientes a los niños que tomen las instituciones públicas o privadas de bienestar social, los tribunales, las autoridades administrativas o los órganos legislativos, una consideración primordial a que se atenderá será el interés superior del niño (ONU, 1989).

Y, finalmente, en relación con lo preceptuado en el acápite 3.2 se estableció que:

Los Estados partes se comprometen a asegurar al niño la protección y el cuidado que sean necesarios para su bienestar, teniendo en cuenta los derechos y deberes de sus padres, tutores u otras personas responsables de él ante la ley y, con ese fin, tomarán todas las medidas legislativas y administrativas adecuadas (ONU, 1989).

La Convención Americana sobre los Derechos Humanos "Pacto de San José de Costa Rica", en su artículo 19 a la letra plantea en relación con los derechos del niño: "todo niño tiene derecho a las medidas de protección que su condición de menor requiere por parte de su familia, de la sociedad y del Estado (Pedroza de la Llave y García, 2003).

Algunos tratados internacionales, aunque no son específicos sobre la infancia, sí prevén cuestiones sobre este grupo social, por ejemplo: La Declaración Universal 
de Derechos Humanos, la Convención Americana sobre Derechos Humano, el Pacto Internacional de Derechos Civiles y Políticos y reconocen el derecho del niño a una protección especial.

La Convención sobre los Derechos del Niño y, en específico, respecto de los niños considerados indígenas, en su artículo 30 prevé:

En los Estados en que existan minorías étnicas, religiosas o lingüísticas o personas de origen indígena, no se negará a un niño que pertenezca a tales minorías o que sea indígena el derecho que le corresponde, en común con los demás miembros de su grupo, a tener su propia vida cultural, a profesar y practicar su propia religión, o a emplear sus propio idioma ( $\mathrm{O}^{\prime}$ Donnell, 2004, p. 849).

El trabajo infantil constituye una violación de los derechos de la niñez. La Convención sobre los Derechos del Niño, reconoce en su numeral trigésimo segundo el derecho a la protección de la niñez contra la explotación económica y el desempeño de cualquier trabajo peligroso o que interfiera con su educación, sea nocivo para su salud y su desarrollo físico y psicológico. Paralelamente, el artículo 31 incluye el derecho al descanso, el esparcimiento, el juego y las actividades recreativas, así como a participar libremente en la vida cultural y artística.

En cuanto a las personas llamadas indígenas, el artículo 1 de la Declaración sobre los Derechos de las Personas Pertenecientes a Minorías Nacionales o Étnicas, Religiosas o Lingüísticas, establece expresamente: "Los Estados protegerán la existencia y la identidad nacional o étnica, cultural, religiosa y lingüística de las minorías dentro de sus territorios respectivos y fomentarán las condiciones para la promoción de esa identidad" (O’Donnell, 2004, p. 849).

Convenio 169 de la Organización Internacional del Trabajo (OIT); prevé derechos de los pueblos indígenas y en su artículo primero define como pueblo indígena a:

Los pueblos en países independientes, considerados indígenas por el hecho de descender de poblaciones que habitaban en el país o en una región geográfica a la que pertenece el país en la época de la conquista o de la colonización o del establecimiento de las actuales fronteras estatales y que, cualquiera que sea su situación jurídica, conservan todas sus propias instituciones sociales, económicas, culturales y políticas o parte ellas (O’Donnell, 2004, p. 884).

La Ley Federal para prevenir y eliminar la discriminación, define discriminación como:

...toda distinción, exclusión, restricción o preferencia que, por acción u omisión, con intención o sin ella, no sea objetiva, racional ni proporcional y tenga por objeto o resultado obstaculizar, restringir, impedir, menoscabar o anular el reconocimiento, goce o ejercicio de los derechos humanos y libertades cuando se base en uno o más de los siguientes motivos: el origen étnico o nacional, el color de la piel, la cultura, el sexo, el género, la edad, 
las discapacidades, la condición social, económica, de salud o jurídica, la religión, la apariencia física, las características físicas, la situación migratoria, el embarazo, la lengua, las opiniones, las preferencias, la identidad o filiación política, el estado civil, la situación familiar, las responsabilidades familiares, el idioma, los antecedentes penales o cualquier otro motivo (Congreso de los Estados Unidos Mexicanos, 2000).

Además, en el cuerpo normativo precitado, se plantea la prohibición de toda práctica discriminatoria que tenga con objeto impedir o anular el reconocimiento y ejercicio de derechos y la igualdad real de oportunidades; estableciendo para ello una serie de acciones afirmativas, entendidas como las medidas especiales, específicas y de carácter temporal, a favor de personas o grupos en situación de discriminación, cuyo objetivo es corregir situaciones patentes de desigualdad en el disfrute o ejercicio de derechos y libertades, aplicables, mientras subsistan dichas situaciones, además que se aplicarán de manera prioritaria a las personas pertenecientes a pueblos indígenas, afro descendientes, mujeres, niñas, niños y adolescentes, personas con discapacidad y personas adultas mayores.

La pretensión, al menos en el discurso normativo es crear redes de protección o tutela a los derechos humanos que garanticen la dignidad de toda persona, en especial, de frente a la vulnerabilidad social en la cual se encuentran la niñez indígena.

\section{CONSIDERACIONES SOBRE EL TÉRMINO INDÍGENA}

\section{a. Concepto}

En este apartado, se atiende a la etimología de indígena, posteriormente, las concepciones propuestas por sociólogos respecto de algunos términos relacionados al vocablo, por ejemplo; indigenismo, grupo social, comunidad y raza.

Indígena vernaculus, in ipsa regione natus (Diccionario Latín Español, Español Latín. p. 923). Indígena es un término que proviene del latín y que significa originario del país de que se trata. En este sentido entonces todos somos indígenas, dado que tenemos un origen.

El indigenismo es el estudio de los pueblos indios iberoamericanos que hoy forman parte de naciones en las que predomina la civilización europea; asimismo, doctrina y partido que propugna reivindicaciones políticas, sociales y económicas para las clases trabajadoras de indios y mestizos en las repúblicas iberoamericanas (RAE).

El sociólogo Fichter menciona que sociólogos y antropólogos han estudiado personas que viven agrupadas y que comparten ciertas características. Ese autor define grupo social como: colectividad identificable, estructurada, continuada, de personas sociales que desempeñan funciones recíprocas conforme a determinadas normas, intereses y valores sociales para la prosecución de objetivos comunes (Fichter, 1993, 
p. 109). Y algunas veces el término comunidad se aplica a categorías sociales que se basan en parecidos étnicos, raciales o religiosos (Fichter, 1993, p. 109).

Otro término relacionado con el de indígena podría ser el de raza. Antropológicamente se trató de aclarar el concepto vulgar de raza, se intentó definirlo como un conjunto de individuos con caracteres corporales semejantes, fijos y hereditarios; sin embargo, algunas de las cosas que la genética ha mostrado, es que lo que se hereda no son los caracteres visibles, sino los genes, que la nueva criatura no hereda la totalidad de los genes de sus dos progenitores, sino solo la mitad de los que aporta cada uno de estos, puede ser que haya una gran cantidad de individuos con una herencia genética semejante, así como sujetos diversos entre sí en cuanto a los caracteres visibles. Cabe también que muchas personas que presenten visibles rasgos físicos semejantes no tengan una herencia común ni tengan tampoco los mismos antepasados. Con estos descubrimientos y otros de la genética, fue criticada la noción vulgar de raza que la antropología en un tiempo intento dar (Recasens, 1991, pp. 326 y 327).

El antropólogo Ashley Montagu sostuvo que jamás tendrían éxito los esfuerzos que se hagan para clasificar los seres humanos, tomando como base sus características corporales visibles; porque no son esos conjuntos de caracteres los que se fijan y se transmiten, sino unas singulares entidades genéticas. La raza solo la veía como expresión del constante cambio genético en una determinada zona (Recasens, 1991, p. y 327).

Entonces, sería erróneo afirmar que lo que determina que alguien sea indígena son tan solo sus rasgos fisonómicos visibles, también incorrecto sería decir que alguien es indígena porque viste un determinado traje típico. No menos válido, es decir que, es indígena quien habla una determinada lengua, porque alguien que no es originario de un determinado lugar puede aprender el idioma que un grupo social habla sin que necesariamente pertenezca a ese grupo social. Por lo tanto, para definir quién es indígena pensamos que hay que tener en cuenta los términos aquí aclarados de indígena, grupo social, comunidades y raza, para tener una correcta concepción acerca de quién debe ser considerado indígena.

Varias legislaciones emplean el término étnico para referirse a los indígenas; etimológicamente étnico es tomado del griego ethnikós que significa "perteneciente a las naciones" (Corominas, 1987).

Lamentablemente los términos indio o indígena han sido empleados discriminatoriamente, como para referirse a personas con atraso cultural o económico. Vale recordar que, antes de la conquista española en México los originarios o nativos mexicanos, económicamente no eran pobres, sino al contrario, eran dueños de sus tierras, las trabajaban y producían; al ser ellos los que sembraban y producían en sus tierras no carecían de lo necesario para sobrevivir, por lo tanto no eran pobres económicamente.

Con la conquista de México por los españoles, los ahora llamados indígenas, fueron despojados de sus tierras y de su riqueza natural, inclusive explotados, 
convirtiéndose en obreros y campesinos marginados, cayendo así en la pobreza económica. Ahora, el ser indígena tiene como una de sus características el ser pobre económicamente, lo que influye para que los derechos fundamentales de las personas se vean vulnerados.

El positivismo mexicano de los liberales considera que entre más parecido sea el país a Europa (es decir entre menos indios existan) más desarrollada y progresista lucirá la nación. Los indígenas y la tenencia comunal de las tierras son calificados como un residuo del pasado que habría que eliminar Gómez, s.f., pp. 205, 207).

La posición de incorporar al indio a la cultura imperante en un país, sirve para avalar la incorporación del indio al sistema capitalista reinante.

El artículo 2 de la Constitución Política de los Estados Unidos Mexicanos hace referencia a la composición pluricultural de la nación mexicana, se reconoce en ese artículo que:

La Nación tiene una composición pluricultural sustentada originariamente en sus pueblos indígenas que son aquellos que descienden de poblaciones que habitaban en territorio actual del país al iniciarse la colonización y que conservan sus propias instituciones sociales, económicas, culturales y políticas, o parte de ellas.

Por lo tanto, las personas consideradas indígenas lejos de pertenecer a grupos sociales con atraso cultural; pertenecen a grupos sociales con mucha tradición y cultura.

Si tenemos en cuenta las consideraciones antes anotadas respecto del término indígena, vemos que lingüísticamente este término no puede significar nada peyorativo, es más, según la raíz latina de la que proviene; todos somos indígenas, en tanto que todos tenemos necesariamente algún origen.

Que alguien sea considerado indígena y pobre económicamente lo hace vulnerable para poder gozar de sus derechos de una manera digna. Agrava esa vulnerabilidad el hecho de ser niña o niño.

\section{b. Organismos internacionales en defensa de la infancia y la adolescencia}

1. La Organización de las Naciones Unidas (ONU).

La ONU nace el 24 de octubre de 1945, se encuentra integrada por casi todas las naciones del mundo, agrupa un total de 193 países soberanos, México ingresó el 7 de noviembre de 1945. Su sede está en Nueva York, este organismo es para dar solución a los problemas que enfrenta toda la humanidad.

2. El Fondo de las Naciones Unidas para la Infancia (Unicef)

En 1946 se crea Unicef, como organismo de la ONU cuyas facultades se destinan de manera exclusiva para la infancia, surge para responder a las necesidades más urgentes de la niñez en Europa, que tras la Segunda Guerra Mundial se encontraba en una situación absolutamente precaria. En octubre de 1953 la Organización se 
transforma en una entidad permanente del sistema de las Naciones Unidas, pero con un papel más amplio: responderá las necesidades a largo plazo de los niños y niñas que viven en la pobreza en los países en desarrollo.

3. El Comité de los Derechos del Niño

Tiene su fundamento en el artículo 43 de la Convención de los Derechos del Niño, como órgano que tiene a su cargo supervisar el cumplimiento de dicha convención.

4. La Organización Internacional del Trabajo (OIT)

La OIT fue creada por el Tratado de Versalles en 1919, como una institución independiente de la sociedad de las naciones, desde su creación, uno de sus principales objetivos lo ha constituido la abolición del trabajo de los niños, por ello, el año mismo de su creación adoptó los convenios 5 y 6 que se refieren, respectivamente, a la edad mínima de admisión al trabajo industrial y al trabajo nocturno (Swepston, 1982).

\section{c. Referente constitucional y ordinario en México de los Derechos de los niños y las niñas}

1. Constitución Política:

Los derechos de los niños y las niñas se encuentran reconocidos en la Carta Política mexicana expresamente en siete numerales diseminados en el cuerpo normativo. Fundamentalmente se determina que en todas las decisiones y actuaciones del Estado mexicano velará y cumplirá por el interés superior de la niñez, tutelando sus derechos, el cual, como principio deberá guiar el diseño, ejecución, seguimiento y evaluación de las políticas públicas dirigidas a la niñez, entre los que se describen los satisfactores de sus necesidades, tales como alimentación, salud, educación, sano esparcimiento, como primordiales para el desarrollo integral. Vinculando además a los ascendientes, tutores y custodios en la obligación de exigir el cumplimiento de los derechos y principio de interés superior. Finalmente, el mismo numeral concede facilidades a los particulares que coadyuven al cumplimiento de los derechos de la niñez.

De acuerdo con lo preceptuado en el numeral segundo de la Constitución mexicana, además de hacer el reconocimiento de una nación pluricultural, literalmente encontramos dos expresiones en relación con los derechos de la niñez, la primera corresponde a la autonomía y libre determinación de las comunidades indígenas para aplicar sus sistemas normativos y solución de conflictos internos, por usos y costumbres, limitados a respetar las garantías individuales, los derechos humanos $\mathrm{y}$, de manera relevante, la dignidad e integridad de las mujeres. Además, impone la obligación de las autoridades estatales de apoyar con programas especiales de educación y nutrición a niños 
y jóvenes de familias migrantes; velar por el respeto de sus derechos humanos y promover la difusión de sus culturas.

En el artículo tercero se desglosa profusamente el derecho a la educación y la obligación del Estado para promover la cultura de protección de los derechos humanos, al correlacionarse con lo preceptuado que delinea la obligación de los mexicanos de que los hijos concurran a las escuelas públicas o privadas.

En relación con el sistema penitenciario, que se contempla en el artículo 18, que define el programa para la reinserción social, se hace referencia especial para los adolescentes en conflicto con la ley penal, que se clasifiquen dentro de los grupos etarios entre 12 años cumplidos y 18 años, a fin de que se les garantice el debido proceso.

Conforme a los procesos de creación normativo, tanto en decretos (artículo 29) como en la producción de leyes del Congreso de la Unión artículo 73, XXIX-P), se limita a las autoridades que sendos instrumentos no podrán restringir ni suspender los derechos de la niñez, y en todo caso la expedición de leyes en materia de derechos de las niñas, niños y adolescentes velando en todo momento por su interés superior.

Finalmente, la expresión literal de la prohibición de la utilización de menores en el trabajo, contiene disposiciones que protegen el trabajo de los mayores de 14 años.

2. Algunas leyes ordinarias de los derechos de los niños y las niñas:

La Ley General de los Derechos de las Niñas, Niños y Adolescentes ${ }^{2}$, de orden público, interés social y de observancia general, que identifica como principios rectores, aunque no describe los alcances de tales principios, por lo que aunque son nominales su amplitud dificulta la exigibilidad; los axiomas que enlista la ley secundaria son:

El interés superior de la niñez; La universalidad, interdependencia, indivisibilidad, progresividad e integralidad de los derechos de niñas, niños y adolescentes, conforme a lo dispuesto en los artículos 1o. y 4o. de la Constitución Política de los Estados Unidos Mexicanos, así como en los tratados internacionales; La igualdad sustantiva; La no discriminación; La inclusión; El derecho a la vida, a la supervivencia y al desarrollo; La participación; La interculturalidad; La corresponsabilidad de los miembros de la familia, la sociedad y las autoridades; La

2 Promulgada en 2014 por el Congreso de la Unión, y que de acuerdo con el cuarto transitorio abroga la Ley para la Protección de los Derechos de Niñas, Niños y Adolescentes (2010), la cual literalmente estableció descriptores amplios para la interpretación del principio de interés superior de la niñez, al indicar que las normas aplicables a niñas, niños y adolescentes, se entenderán dirigidas a procurarles, primordialmente, los cuidados y la asistencia que requieren para lograr un crecimiento y un desarrollo plenos dentro de un ambiente de bienestar familiar y social. Atendiendo a este principio, el ejercicio de los derechos de los adultos no podrá, en ningún momento, ni en ninguna circunstancia, condicionar el ejercicio de los derechos de niñas, niños y adolescentes. La aplicación de esta ley atenderá al respeto de este principio, así como al de las garantías y los derechos fundamentales reconocidos en la Constitución Política de los Estados Unidos Mexicanos. 
transversalidad en la legislación, políticas públicas, actividades administrativas, económicas y culturales; La autonomía progresiva; El principio pro persona; El acceso a una vida libre de violencia, y La accesibilidad.

Por otra parte, debe mencionarse a la Ley nacional del sistema integral de justicia penal para adolescentes, uno de las últimas legislaciones que concretaron su alienación al sistema penal acusatorio mexicano, promulgada el 16 de junio de 2016. Contempla una diversidad de ajustes con relación al sistema de adultos, partiendo de que se soporta en los presupuestos del paradigma del garantismo penal, de la consideración de persona y sujeto de derecho al adolescente implicado en materia penal y, por tanto, obligado a la protección de los derechos fundamentales, procesales y de las garantías de tutela de ambos.

De acuerdo con lo señalado por Huertas,

dicho sistema debe cumplir con procedimientos de carácter pedagógico, específico y diferenciado del sistema de adultos tanto en el proceso como en las sanciones, dirigido a los adolescentes mayores de doce años y menores de dieciocho (sujetos de especial protección constitucional) en conflicto con la ley penal e inspirado en un paradigma de protección integral y corresponsabilidad de la sociedad, el Estado y la familia que busca dotar al adolescente de las herramientas necesarias para llevar a cabo actividades productivas (Huertas y Morales, 2013, p. 70).

\section{d. Vulnerabilidad}

Ejemplificativamente, la Ley General de los Derechos de Niñas, Niños y Adolescentes establece en su artículo 10, prevé a esta condición de vulnerabilidad de este sector social en tanto que, entendido por esta a las circunstancias específicas de carácter socioeconómico, alimentario, psicológico, físico, discapacidad, identidad cultural, origen étnico o nacional, situación migratoria o apátrida, o bien, relacionadas con aspectos de género, preferencia sexual, creencias religiosas o prácticas culturales, $\mathrm{u}$ otros que restrinjan o limiten el ejercicio de sus derechos.

Erika Strand (Diario el Sol de Torreón, 2016), jefa de la política pública de Unicef México, determinó que de acuerdo con el Informe del "Estado mundial de la infancia 2016", la situación para México es que en 2014, nueve de cada 10 menores que hablan una lengua indígena estaban en pobreza, mientras que 21.4 millones de la población total del país de 0 a 17 años, se encontraba en la misma condición, otro dato del informe es que para el mismo año, el 23.75 por ciento de las mujeres mexicanas se casaron por primera vez antes de cumplir los 18 años de edad, la mayor incidencia se da en estados como Chiapas, Guerrero y Oaxaca, respectivamente, además que dos de cada mil niñas y adolescentes de 10 a 14 años procrearon cuando menos un hijo.

En el reporte sobre la discriminación en México 2012, del Consejo Nacional para Prevenir la Discriminación (CONAPRED) se informa que: en México, 10.7 por ciento de la población entre 5 y 17 años de edad trabaja. Esto quiere decir que 3.015.067 
de niños, niñas y adolescentes, en el mejor de los casos combinan sus actividades escolares con un trabajo. La realidad indica que la mayoría ha abandonado la escuela para dedicarse de tiempo completo al empleo (De la Madrid, 2012, p. 50). La situación de pobreza de la niñez mexicana, en especial es aquella que vive en zonas rurales o conurbadas, es reconocida en este informe.

Junto con la problemática descrita, debe agregarse que esta condición de exposición y vulnerabilidad de las niñas, niños y adolescentes ante delitos específicos, tales como la trata de persona, pornografía infantil, abuso sexual, matrimonio infantil, y otros fenómenos sociales como el reclutamiento por la delincuencia organizada.

Esta expresión de vulnerabilidad, y de la debida diligencia que debe ofrecer el operador jurídico dentro del sistema de procuración e impartición de justicia, ya la había advertido desde 2010 la Corte Interamericana de Derechos Humanos, a propósito del Caso Rosendo Cantú y otra vs. México, en Sentencia de 31 de agosto de 2010, donde al verse involucrados menores indígenas, puntualizó acciones específicas de intervención, tales como:

...máxime por tratarse de una persona indígena, pues los niños indígenas cuyas comunidades son afectadas por la pobreza se encuentran en una especial situación de vulnerabilidad. La obligación de proteger el interés superior de los niños y niñas durante cualquier procedimiento en el cual estén involucrados puede implicar, inter alia, lo siguiente: i) suministrar la información e implementar los procedimientos adecuados adaptándolos a sus necesidades particulares, garantizando que cuenten con asistencia letrada y de otra índole en todo momento, de acuerdo con sus necesidades; ii) asegurar especialmente en casos en los cuales niños o niñas hayan sido víctimas de delitos como abusos sexuales u otras formas de maltrato, su derecho a ser escuchados se ejerza garantizando su plena protección, vigilando que el personal esté capacitado para atenderlos y que las salas de entrevistas representen un entorno seguro y no intimidatorio, hostil, insensible o inadecuado, y iii) procurar que los niños y niñas no sean interrogados en más ocasiones que las necesarias para evitar, en la medida de lo posible, la revictimización o un impacto traumático en el niño (CIDH, 2017, pp. 8-9).

Lo anterior culminó con la aprobación del Protocolo de actuación para quienes imparten justicia en casos que involucren a niños, niñas y adolescentes de 2014 (Suprema Corte de Justicia de la Nación, 2014), que se erige como una herramienta de apoyo para la labor judicial en la medida en que sistematiza cuáles son los principios de carácter general que deben ser considerados como referentes cuando se tiene un asunto que involucra directa o indirectamente a un niño, niña o adolescente, bajo la premisa de su consideración sustancial y sustantiva como persona, y por ende, a quien se le debe respetar todos los derechos humanos y procesales que ello implica. 


\section{MECANISMOS DE TUTELA JURISDICCIONAL EN FAVOR DE NIÑAS, NIÑOS Y ADOLESCENTES CONSIDERADOS INDÍGENAS EN OAXACA}

Las condiciones de inequidad y discriminación hacia la infancia considerada indígena imperan en Oaxaca, se identifica por una doble exclusión en los ámbitos familiar y comunitario. Así mismo, se da una invisibilidad hacia ese sector de la población, porque a veces no se les considera en los programas nacionales, diseñados casi exclusivamente para la población urbana y esa problemática es poco estudiada por investigadores o académicos en Oaxaca.

Con relación a esta cuestión, la Declaración de las Naciones Unidas sobre los derechos de los pueblos indígenas, en su artículo 21 establece que los estados adoptaran medidas eficaces y cuando proceda medidas especiales para asegurar el mejoramiento cotidiano de sus condiciones económicas y sociales, prestando particular atención a los derechos y necesidades especiales de los ancianos, las mujeres, los jóvenes, los niños y las personas indígenas con discapacidad.

El bloque de constitucionalidad, como ya se ha indicado, estable como objeto garantizar a niñas, niños y adolescentes la tutela y el respeto de los derechos fundamentales reconocidos en nuestra Carta Magna.

A mayor abundamiento, se prevé que los Estados adoptaran medidas, conjuntamente con los pueblos indígenas, para asegurar que los niños indígenas gocen de protección y garantías plenas, contra todas las formas de violencia y discriminación. Así mismo, el apartado B, fracción VIII del artículo $2^{\circ}$ de la Constitución Federal establece que para abatir las carencias y rezagos que afectan a los pueblos y comunidades indígenas, los Estados tienen la obligación de apoyar con programas especiales de educación y nutrición a niños y jóvenes de familias migrantes.

En esas circunstancias, y atendiendo a las recomendaciones realizadas por los diversos mecanismos del Sistema de Naciones Unidas, en particular lo expresado por el Dr. Rodolfo S. Stavenhagen, relator especial sobre la situación de los derechos humanos y libertades fundamentales de los indígenas, que en el informe sobre su visita oficial a México, realizada en el 2003, recomendó:

...Con base en el texto constitucional como norma mínima, y mientras no se reforme de nuevo, se recomienda a las legislaturas de los estados que elaboren en consulta estrecha con los pueblos indígenas la legislación correspondiente para el reconocimiento, la protección y la promoción de los derechos humanos fundamentales de los pueblos indígenas de cada entidad (Stavenhagen, 2013).

Con fecha 9 de agosto del año 2013 se entregó la propuesta de iniciativa de reforma a la Constitución Política del Estado libre y soberano de Oaxaca sobre derechos de los pueblos indígenas y negro-afromexicanos de Oaxaca, derivado del proceso que 
trató de impulsar una reforma constitucional, en la cual se desarrolló la consulta en 24 foros regionales, un foro Estatal, 6 sesiones del Consejo Consultivo y múltiples reuniones del Comité Técnico de Expertos, en la que participó la Secretaría de Asuntos Indígenas y el Consejo Consultivo de los Pueblos Indígenas y Afromexicano (Comité Técnico de Expertos et al., 2013, pp. 148-150), sustancialmente se propuso adicionar un párrafo vigésimo tercero al artículo 12 Constitucional local, a fin de que, expresamente se garantice el ejercicio y acceso pleno a los derechos a la vida, a la alimentación, a la integridad física y emocional, a preservar su identidad, a una vida libre de violencia, al desarrollo y protección integrales, a una educación comunitaria indígena e intercultural, y a la participación en todos los ámbitos, en condiciones de igualdad, no discriminación y no subordinación.

De igual manera, en la fracción II del artículo 112 constitucional, se propone establecer que en la jurisdicción indígena, al aplicar sus sistemas normativos, se respete la dignidad e integridad de la niñez.

Además, se propone que la educación responda a las realidades culturales lingüísticas, artísticas, espirituales, ecológicas y económicas. Se fomente el respeto y conocimiento de la diversidad cultural y lingüística de la entidad; para ello se establece que el Estado garantice e imparta una educación comunitaria, indígena y con perspectiva intercultural, en todos los ámbitos y niveles. Se debe exigir que los docentes tengan el perfil requerido, incluyendo el conocimiento de la cultura regional y el dominio de la legua indígena.

\section{a. Referente legal oaxaqueño}

Cabe destacar, que el referente legal específico para el Estado Libre y Soberano de Oaxaca se encuentra, en los artículos 1 y 112 de la Constitución Política para el Estado Libre y Soberano de Oaxaca.

Artículo 1. El estado de Oaxaca es multiétnico, pluricultural y bilingüe, parte integrante de los Estados Unidos Mexicanos, libre y soberano en todo lo que concierne a su régimen interior.

En el Estado de Oaxaca todas las personas gozarán de los derechos humanos reconocidos en la Constitución Política de los Estados Unidos Mexicanos, los tratados internacionales de los que el Estado mexicano sea parte y de esta Constitución. El poder público garantizará su protección, cuyo ejercicio no podrá restringirse ni suspenderse, salvo en los casos y bajo las condiciones que la Constitución Política de los Estados Unidos Mexicanos establece.

La interpretación de las normas relativas a los derechos humanos se hará conforme a lo establecido en la Constitución Política de los Estados Unidos Mexicanos, favoreciendo en todo tiempo a las personas la protección más amplia. Para el ejercicio de los derechos humanos y las garantías constitucionales no se exigirán condiciones o requisitos que no estén establecidos en la Constitución o la ley. Ninguna norma jurídica podrá restringir los derechos humanos ni sus garantías. 
Las autoridades del Estado, en el ámbito de sus competencias, tienen la obligación de promover, respetar, proteger y garantizar los derechos humanos, de conformidad con los principios de universalidad, interdependencia, pluriculturalidad y progresividad. El Estado deberá prevenir, investigar, sancionar y reparar las violaciones a los derechos humanos, en los términos que establezcan las leyes. En el caso de aquellos que se reserve el pueblo de Oaxaca, serán protegidos mediante el Juicio para la Protección de los Derechos Humanos. Todas las autoridades están obligadas a que en sus determinaciones o resoluciones que pronuncien deben de aplicar el control difuso, el control de constitucionalidad y el control de convencionalidad en materia de derechos humanos.

Artículo 112. La Jurisdicción Indígena se ejercerá por las autoridades comunitarias de acuerdo con los usos y costumbres de los pueblos y comunidades indígenas, dentro del marco del orden jurídico vigente y en los términos que determine la Ley Reglamentaria del artículo 16 de esta Constitución.

\section{b. Jurisprudencia}

El interés superior del menor como derecho reconocido, no es nuevo, ya que este se ha acuñado tanto en el derecho anglosajón como en el codificado; y además ha sido objeto de interpretación y reconocimiento, tanto en los tratados internacionales como por el más alto tribunal de nuestro país.

La Primera Sala de la Suprema Corte de la Nación en su publicación de julio de 2014 emitió diversas tesis por reiteración sobre el interés superior del niño ${ }^{3}$, ponderando por un lado su conceptualización y, por el otro, reconociéndolo como un principio orientador de la actividad interpretativa relacionada con cualquier norma jurídica que deba aplicarse a un menor.

En esta tesitura y por cuanto hace su conceptualización denomina al interés jurídico un concepto indeterminado por considerar que para definirlo es necesario encontrar criterios para averiguar racionalmente en qué consiste, y paralelamente determinarlo en criterios de casos concretos, para lo cual dichos criterios deben estructurarse por zonas; a) zona de certeza positiva, b) zona de certeza negativa y c) una zona indeterminada.

Por otro lado, y en cuanto a que lo considera un principio orientador, le otorga esta naturaleza, dado que nace del artículo cuarto constitucional en el sentido que ha de guiar cualquier decisión del juzgador; pues este principio ordena la realización de una interpretación sistemática que para darle sentido a la norma en cuestión, debe tomar en cuenta los deberes de protección de la niñez; en consecuencia, es un elemento que ha de tomar el juez al momento de motivar su decisión, por ejemplo sobre la guarda y custodia de menores de edad.

3 A la fecha, en el sistema de consulta de la Suprema Corte de Justicia de la Nación, a la voz de "interés superior de la niñez" se enlistas 63 rubros de precedentes y jurisprudencias con tal indicador, por lo que se advierte que la labor interpretativa del máximo órgano judicial mexicano ha sido prolífero. 
De igual manera y atendiendo a lo dispuesto por el artículo 12 sobre la Convención de los Derechos del Niño, en tesis jurisprudencial la Suprema Corte de Justicia de la Nación en el 2015 considera el ejercicio del derecho de los menores a participar en los procedimientos que afecten su esfera jurídica, toda vez que estos tienen derecho a expresar libremente su opinión en los asuntos que los afecten.

Otro criterio (Suprema Corte de Justicia de la Nación, 2015), se dimensiona en constituirse como un elemento de interpretación, de tal manera que:

El interés superior del menor tiene un contenido de naturaleza real $y$ relacional, que demanda una verificación y especial atención de los elementos concretos y específicos que identifican a los menores, por lo que el escrutinio que debe realizarse en controversias que afecten dicho interés, de forma directa o indirecta, es más estricto que el de otros casos de protección a derechos fundamentales. Particularmente, en el ámbito jurisdiccional el interés superior del menor es tanto un principio orientador como una clave heurística de la actividad interpretativa relacionada con cualquier norma jurídica que deba aplicarse a un niño en un caso concreto o que pueda afectar sus intereses. Así, el interés superior del menor ordena la realización de una interpretación sistemática que considere los deberes de protección de los menores y los derechos especiales de éstos previstos en la Constitución Política de los Estados Unidos Mexicanos, en los tratados internacionales y en las leyes de protección de la niñez; de este modo, el principio del interés superior del menor se consagra como criterio orientador fundamental de la actuación judicial; de ahí que conlleva ineludiblemente a que el juzgador tome en cuenta, al emitir sus resoluciones, algunos aspectos que le permitan determinar con precisión el ámbito de protección requerida, tales como la opinión del menor, sus necesidades físicas, afectivas y educativas; el efecto sobre él de un cambio; su edad, sexo y personalidad; los males que ha padecido o en que puede incurrir, y la posibilidad de que cada uno de sus padres responda a sus posibilidades. En suma, el principio del interés superior del menor debe informar todos los ámbitos de la actividad estatal que estén relacionados directa o indirectamente con los menores, lo que necesariamente implica que la protección de los derechos del niño se realice a través de medidas reforzadas o agravadas, ya que los intereses de los niños deben protegerse siempre con una mayor intensidad (Gaceta del Semanario Judicial de la Federación, 2015, p. 1397) (resalte propio).

\section{CONCLUSIONES}

El derecho del niño a una protección especial se vincula con el concepto de desarrollo integral del niño y de su libertad y dignidad, dimensionada la importancia del "Interés Superior del Niño", como principio que debe orientar toda la legislación relativa a los asuntos de los niños, así como la actuación de cualquier operador jurídico, 
instituciones públicas y privadas. Dicho de otra forma y en términos generales, se puede entender por la rectoría que este principio plantea como directiva todo aquello que favorezca su desarrollo físico, psicológico, moral y social para lograr el pleno y armonioso desenvolvimiento de su personalidad.

A la fecha los menores de edad llamados indígenas, consideramos que, sufren los efectos de la desigualdad económica, propios del sistema político y económico que se acendra en ciertas regiones y grupos sociales en México. Hay descuido de las autoridades respecto del tema y falta de aplicación de las normas internacionales y estatales. El estado de Oaxaca no ha logrado erradicar ese problema, pese a la existencia de leyes internacionales y locales creadas para el efecto de la protección y defensa de los derechos humanos de las niñas, niños y adolescentes llamados indígenas.

Es en la Declaración de los Derechos del Niño y en la Convención sobre los Derechos del Niño donde se estipula el principio: "Interés Superior del Niño", ello para México, junto con los criterios del control difuso de la convencionalidad, de la interpretación, conforme del principio pro-persona, y de ellos el pro debilis. En suma, en la Convención, se prevé que todas las medidas respecto del niño deben estar basadas en la consideración del interés superior de este, y que corresponde al Estado asegurar una adecuada protección y cuidado, cuando los padres o madres u otras personas responsables no tienen capacidad para hacerlo.

Los derechos de los niños y las niñas indígenas se rigen bajo principios propios, que son esencialmente diferentes a los que norman el derecho en general, de tal forma, que su interpretación se hará de conformidad con el bloque de constitucionalidad y las decisiones de la Corte Interamericana de Derechos Humanos, integrándose de este modo, el ordenamiento jurídico mexicano al internacional.

Los derechos de los niños y las niñas indígenas forman una normativa a aplicarse en los distintos ámbitos en los cuales estos se desarrollan, fundamentalmente en el seno de la familia, en la escuela y en general ante la sociedad, sectores respecto de cuales recae el deber de cumplirlos, complementando por la acción de protección y defensa que debe asumir el Estado, un deber fundamentalmente ético y moral, que refleja los valores en los cuales se fundamentan el derecho, pero que también son cualidades inherentes a los seres humanos.

En Oaxaca no existe una tutela extensiva de protección adecuada para que los niños y las niñas indígenas, no sean víctimas de violencia y maltrato, la familia y la escuela se convierten en los lugares donde se presenta la mayor parte de los abusos físicos, laborales, psicológicos y sexuales, en contra de los niños y las niñas indígenas, en lugar de ser espacios de protección y seguridad para los menores de edad y para sus familiares, pues de acuerdo con Huertas, también

Se incluye a los familiares o personas a cargo que tengan relación inmediata con la víctima directa, y a las personas que hayan sufrido daños al intervenir para asistir a la víctima en peligro o para prevenir la victimización (Huertas, 2009, p. 16). 
El niño o la niña indígena, al ser integrado a su familia de origen, que sea capaz de proporcionarle un ambiente adecuado de amor, valores, respeto, comprensión y tolerancia, así como la satisfacción de todas sus necesidades materiales, culturales y de educación, permitirá a ese ser de crecimiento su inserción sana a la sociedad, en la cual actuarán como personas de bien. Al logro de estos satisfactores debe orientarse el Estado mexicano, con políticas públicas holísticas, trasversales y de largo plazo, que sean continuas, y que superen la condición sexenal de la vida política nacional.

Desde una perspectiva histórica son innegables los avances logrados sobre el reconocimiento o validez del derecho indígena en el derecho nacional en los años recientes: ante los rezagos académicos se ha generado una lluvia de reflexiones multidisciplinarias que enriquece el proceso; ante rezagos políticos tenemos 16 constituciones locales y la federal que reconocen la existencia de pueblos indígenas; ante los rezagos políticos se ejerce el derecho a la autonomía en Oaxaca.

La constante hasta ahora es que el reconocimiento del derecho indígena por el Estado se ha encontrado sujeto a los vaivenes político-electorales, y hasta emocionales, de los ejecutivos locales y federal, así como de los legisladores, es decir, de la población no indígena que ha ejercido, históricamente el monopolio de la producción de normas. Si se quiere intentar corregir esta tendencia se tendría que ir incorporando personal a las instancias ejecutivas, legislativas y judiciales del Estado, con conocimientos de las lenguas y culturas de los pueblos indígenas.

Parte de este proceso podría considerar la posibilidad de convocar a nuestros congresos constituyentes para darnos constituciones (federal y locales), con representantes de los pueblos indígenas, que respondan a la demanda de respeto a las diferencias culturales para que las relaciones sociales sean igualitarias, y respondan a la demanda de solidaridad social para que las condiciones de vida de la mayor parte de la población de este país sean dignas, especialmente tratándose de los derechos del niño y niña indígena.

\section{REFERENCIAS}

Carbonell, M. (2002). Comentarios a la Reforma Constitucional en Materia Indígena. México, Instituto de Investigaciones Jurídicas.

Cillero, M. (s.f.). El interés superior del niño en el marco de la convención sobre los derechos del niño.

Comité Técnico de Expertos, Consejo Consultivo de los Pueblos Indígenas y Afromexicano de Oaxaca; Secretaría de Asuntos Indígenas del Gobierno del Estado de Oaxaca (2013). Hacia el reconocimiento de un estado multicultural, en el marco del pluralismo jurídico (pp. 148-150). Oaxaca de Juárez, Oaxaca.

Congreso de los Estados Unidos Mexicanos (2000, mayo). Ley para la Protección de los Derechos de Niñas, Niños y Adolescentes. Cámara de Diputados Congreso de la Unión. Recuperado de http://www.gob.mx/cms/uploads/attachment/ file/211050/10_Ley_para_la_Protecci_n_de_los_Derechos_de_Ni_as_Ni os_y_Adolescentes.pdf 
Congreso de los Estados Unidos Mexicanos (2014). Ley general de los derechos de las niñas, niños y adolescentes. México. Recuperado de http://www.diputados. gob.mx/LeyesBiblio/pdf/LGDNNA_041214.pdf

Congreso de los Estados Unidos Mexicanos (2016). Ley federal para prevenir y eliminar la discriminación. México. Recuperado de http://www.diputados.gob. $\mathrm{mx} /$ LeyesBiblio/pdf/262_011216.pdf

Congreso de los Estados Unidos Mexicanos (2017). Constitución Política de los Estados Unidos Mexicanos. México. Recuperado de http://www.diputados.gob. $\mathrm{mx} /$ LeyesBiblio/pdf/1_240217.pdf

Corominas, J. (1987). Breve diccionario etimológico de la Lengua Castellana. Madrid: Editorial Gredos. Recuperado de https://isaimoreno.files.wordpress. com/2017/03/diccionario-etimolocc81gico-abreviado-de-la-lengua-castellanajoan-corominas.pdf

Corte Interamericana de Derechos Humanos. (2017). Niños, niñas y adolescentes. Cuadernillo de la Jurisprudencia de la Corte Interamericana de Derechos Humanos, No. 5. (Actualización). San José, Costa Rica. Recuperado de http:// www.corteidh.or.cr/sitios/libros/todos/docs/ninosninas3.pdf

Dávila, P., y Naya, L.M. (2006). Evolución de los derechos de la infancia en América Latina. En P. Dávila y L.M. Naya. (Comps.). Derechos de la infancia y educación inclusiva en América Latina. Buenos Aires: Granica.

De la Madrid, R.R. (Coord.). (2012, octubre). Reporte sobre la discriminación en México 2012 (p. 50). Trabajo Consejo Nacional para Prevenir la Discriminación, México. Recuperado de http://www.conapred.org.mx/urserfiles/files/ reporte_2012_trabajo.pdf

Diario el Sol de Torreón (2016, junio 28). Niños indígenas, los de mayor desventaja en México: Unicef. México, Recuperado de https://www.elsiglodetorreon. com.mx/noticia/1238001.ninos-indigenas-los-de-mayor-desventaja-enmexico-unicef.html

Diccionario Latín - Español, Español- Latín. Recuperado de https://es.glosbe.com/la/es

Diccionario de la lengua española. Recuperado de http://www.rae.es/obrasacademicas/diccionarios/diccionario-de-la-lengua-espanola

Fichter, J.H. (1993). Sociología (17 ed.). Editorial: Herder.

Garrido, R. (2013). El interés superior del niño y el razonamiento jurídico. Revista de la Biblioteca Jurídica Virtual del Instituto de Investigaciones Jurídicas de la UNAM. Recuperado de biblio.juridicas.unam.mx/revista/pdf/ FilosofiaDerecho/7/arl/arl8.pdf

Gómez, F.A. (s.f.). Sociología. México: Editorial Porrúa.

González, N., y Rodríguez, S. (s.f.). El interés superior del menor. Contexto conceptual. p. 22.

Huertas, O. (2009). Perspectiva victimológica de la explotación sexual comercial de niños, niñas y adolescentes en Colombia. Revista Logos Ciencia \& Tecnología, 1(1). Bogotá, Colombia. 
Huertas, O. (2016, septiembre-diciembre). David Matza: perspectiva criminológica de la deriva a la delincuencia juvenil. Revista Criminalidad, 58(3). Bogotá, D. C., Colombia.

Huertas, O., y Morales, I.R. (2013, julio-diciembre). El sistema de responsabilidad penal para adolescentes: la expansión de la punibilidad en el neopunitivismo colombiano. Revista Guillermo de Ockham, 11(2). Cali, Colombia.Instituto Nacional de Estadística y Geografía (2016, agosto 5). Estadísticas a propósito del día internacional de los pueblos indígenas (9 de agosto). Recuperado de http://www.inegi.org.mx/saladeprensa/aproposito/2016/indigenas2016_0.pdf

Jiménez, F.J. (2001). Derechos de los niños, Instituto de Investigaciones Jurídicas de la UNAM (pp. 7-9). Recuperado de https://books.google.com.mx/ books?isbn $=9683690254$

Manrique, F.E.R., Gómez, W., Martínez, L.E. (2015, julio-diciembre). Los retos y dificultades operativas del control de convencionalidad: una mirada desde el sistema jurídico mexicano. Revista Conflicto \& Sociedad, 3(2), UNISABANETA

Molina, M.R., Huerta, O., Suárez, Y.Y. (2017). Responsabilidad penal adolescente: sistema protector o represor. Revista UBI SOCIETAS IBI IUS, IV(VI), Universidad Autónoma de Chihuahua.

Oaxaca, Estado Libre y Soberano de Oaxaca (2016). Constitución Política para el Estado Libre y Soberano de Oaxaca. Periódico Oficial del Estado. 15-04-1922. (Última reforma). Recuperado de www.ordenjuridico.gob.mx

O’Donnell, D. (2004). Derecho Internacional de los Derechos Humanos. Normativa, jurisprudencia y doctrina de los sistemas universal e interamericano. (Opinión consultiva OC-17/2002 de la Corte Interamericana de Derechos Humanos).

Organización de las Naciones Unidas (1989). Convención sobre los derechos del niño. Recuperado de https://www.unicef.org/ecuador/convencion(5).pdf

Pedroza de la Llave, S.T., y García, O. (Comps.). (2003). Compilación de instrumentos Internacionales de Derechos Humanos Firmados y Ratificados por México 1921-2003 (Tomo I). Comisión Nacional de los Derechos Humanos. México. Recuperado de http://discursoforense.unam.mx/sites/default/files/archivos/ publicaciones/comp instrumentos t1.pdf

Presidencia de la República de Nicaragua. (1998). Código de la Niñez y la Adolescencia. Ley No. 287, del 24 marzo 1998.

Recasens, L. (1991). Tratado general de sociología. México: Editorial Porrúa.

Stavenhagen, R. (s.f.). La situación de los derechos humanos de los pueblos indígenas en México. En Estudios y debates sobre multiculturalismo. Y derecho indígena desde las visiones (p. 182). México, España.

Stavenhagen, R. (2013, diciembre 23). Informe del relator especial sobre la situación de los derechos humanos y libertades fundamentales de los indígenas. Adición Misión a México. E/CN.4/2004/Add.2 
Suprema Corte de Justicia de la Nación. México. (2013, abril). Época: Décima Época, Registro: 2003284, Instancia: Primera Sala, Tipo de Tesis: Aislada. Semanario Judicial de la Federación y su Gaceta, Libro XIX, Tomo 1, Materia(s): Constitucional, Tesis: 1a. XCIX/2013 (10a.).

Suprema Corte de Justicia de la Nación. México. (2014). Protocolo de actuación para quienes imparten justicia en casos que involucren a niños, niñas y adolescentes. Recuperado de https://www.sitios.scjn.gob.mx/codhap/sites/default/files/ archivos/paginas/protocolo_infancia_2da_version.pdf

Suprema Corte de Justicia de la Nación. México. (2015, febrero). Primera Sala, Época: Décima Época, Registro: 2008546, Tipo de Tesis: Aislada. Gaceta del Semanario Judicial de la Federación, Libro 15, Tomo II. Materia(s): Constitucional, Tesis: 1a. LXXXIII/2015 (10a.) (Nota: Esta tesis es objeto de la denuncia relativa a la contradicción de tesis 418/2016, pendiente de resolverse por el Pleno de la Suprema Corte de Justicia de la Nación).

Suprema Corte de Justicia de la Nación, México. (2017, enero). Segunda Sala, Tipo de Tesis: Aislada. Gaceta del Semanario Judicial de la Federación, Libro 38, Tomo I. Materia(s): Constitucional, Tesis: 2a. CXLI/2016 (10a.).

Swepston, L. (1982, julio-septiembre). Trabajo de los niños. Revista Internacional del Trabajo, 101(3). Ginebra, Suiza.

Unicef. (2013). Los derechos de la infancia y adolescencia en Oaxaca. Centro de Investigación y Estudios Superiores en Antropología Social (CIESAS), Unidad Pacífico Sur y Unicef México. 